\title{
Methodology to assess coastal infrastructure resilience to climate change
}

\author{
Marta Roca ${ }^{1, a}$, Dominic Hames ${ }^{1}$, Ben Gouldby ${ }^{1}$, Eleni S. Zve ${ }^{1}$, Olwen Rowlands ${ }^{2}$, Peter Barter ${ }^{2}$ and Jo Grew ${ }^{3}$ \\ ${ }^{1}$ HR Wallingford, Howbery Business Park. Crowmarsh Gifford, Wallingford, Oxfordshire, OX10 8BA, United Kingdom \\ ${ }^{2} \mathrm{CH} 2 \mathrm{M}$ Hill, Burderop Park, Swindon, SN4 OQD, United Kingdom \\ ${ }^{3}$ Network Rail, Western House, 1 Holbrook Way, Swindon, Wiltshire, SN1 1BD, United Kingdom
}

\begin{abstract}
The section of railway which runs along the coastline of south Devon in United Kingdom, from Exeter to Newton Abbot, is one of the most photographed sections of railway in the world. It was opened in 1846 with embankments and seawalls protecting and supporting the railway, providing the route of an atmospheric railway. Despite regular maintenance however, there has been a history of storm damage, one of the most severe occurring in February 2014. This resulted in the collapse of the line, interruption of all rail traffic into and out of the far SouthWest of the United Kingdom (affecting parts of Devon and the whole of Cornwall) and significant damage to the region's economy.

In order to improve the resilience of the line, several options have been considered to evaluate and reduce climate change impacts to the railway. This paper describes the methodological approach developed to evaluate the risks of flooding for a range of scenarios in the estuary and open coast reaches of the line. Components to derive the present day and future climate change coastal conditions including some possible adaptation measures are also presented together with the results of the hindcasting analysis to assess the performance of the modelling system. An overview of the modelling results obtained to support the development of a long-term Resilience Strategy for asset management is also discussed.
\end{abstract}

\section{Introduction}

In the United Kingdom, the south-west mainline railway that runs along the coastline of south Devon from Exeter to Newton Abbot was opened in 1846, built to the designs of Isambard Kingdom Brunel. Since this date, it has proved to be an important link for the population of South Devon and Cornwall, playing a vital part in the region's economy both in terms of the role it plays in terms of the transportation of local residents and of the large number of tourists who visit these areas.

However, despite regular maintenance, there has been a history of storm damage along this line, one of the most severe occurring in February 2014. This resulted in the collapse of the line, interruption of all rail traffic into and out of the far South-West of England and significant damage to the economy of Devon and Cornwall.

With sea levels currently rising by about $3.3 \mathrm{~mm} / \mathrm{year}$ [1], and local land levels falling by approximately $1.0 \mathrm{~mm} /$ year [2], the potential threat to this stretch of coastline has been exacerbated in recent years. Therefore, the vulnerability of the infrastructure as a result of weather-induced disruption is being considered as part of a long term resilience strategy being developed by Network Rail, the owner of the infrastructure.

The extent of line considered, some $30 \mathrm{~km}$ long, is shown in Figure 1. Alongside the exposed open-coast frontage between Dawlish Warren and Teignmouth there

\footnotetext{
a Corresponding author: m.roca@hrwallingford.co.uk
}

are the more sheltered estuary frontages along the Exe and Teign.

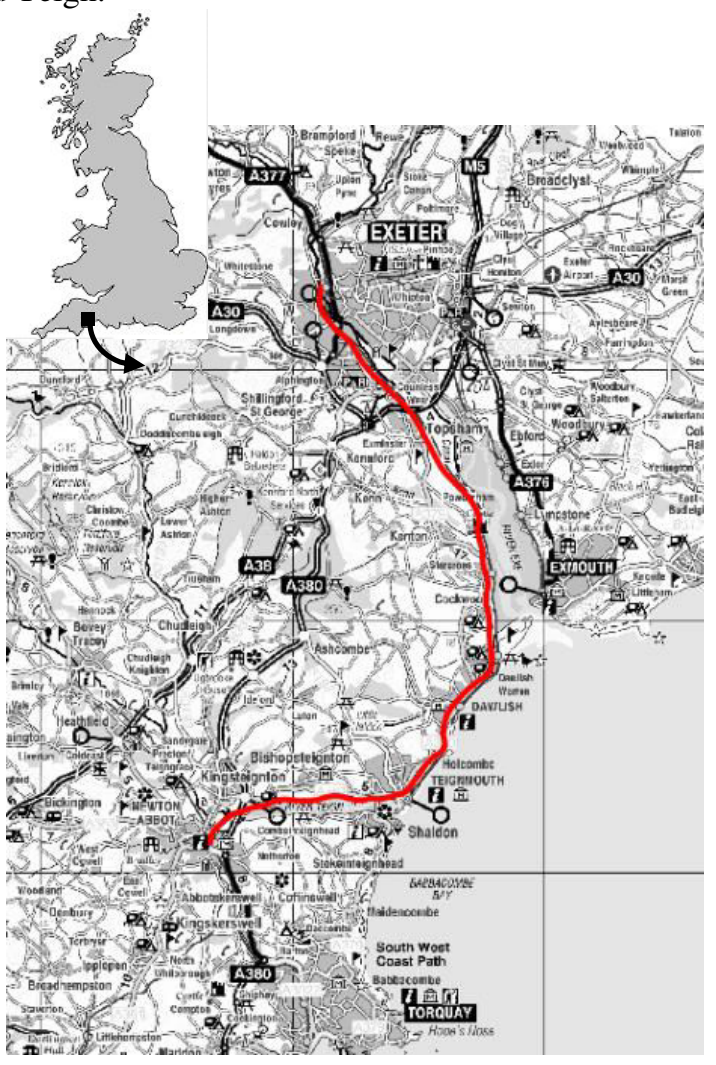

Figure 1. Area of study (with railway shown in red) 
The open-coast frontage consists of a mix of lowlevel mixed sand and shingle beaches.

The main defences in the area are vertical stone walls with a few groynes, perpendicular to the beach, to control longshore sediment movement (Figure 2).
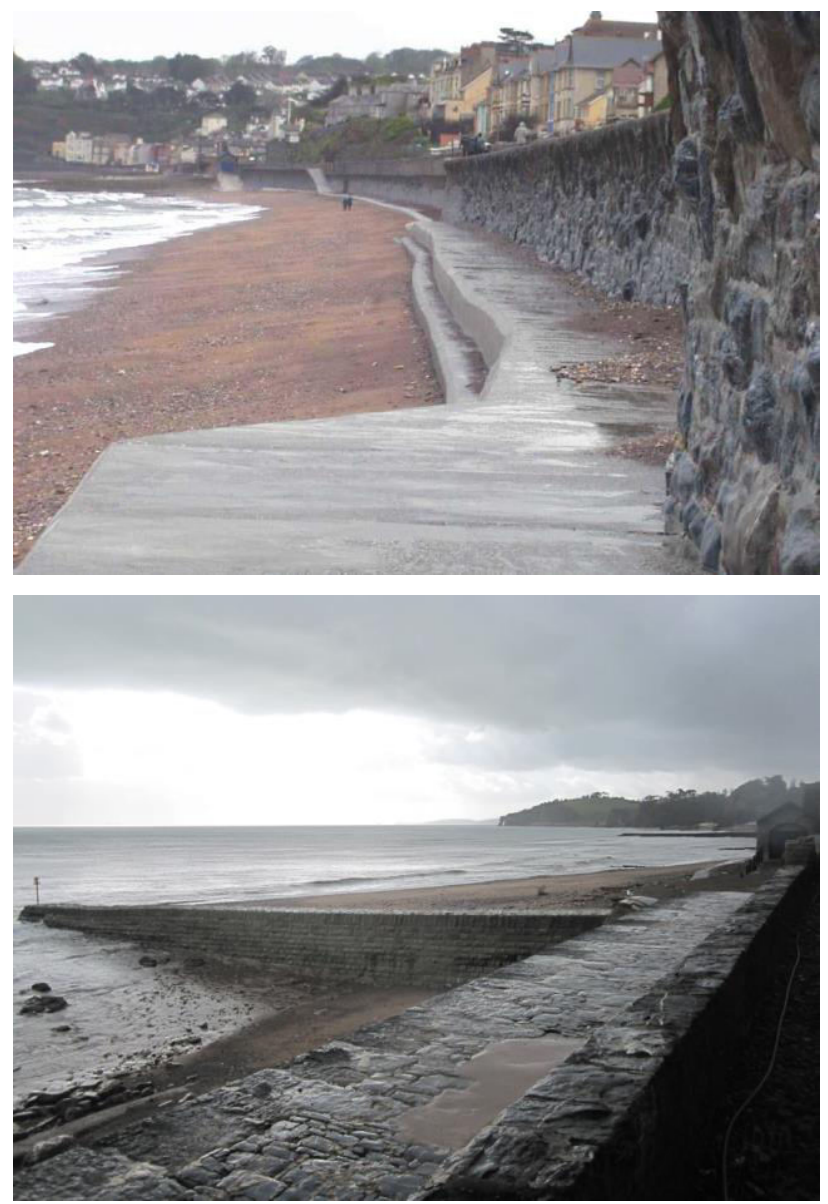

Figure 2. Examples of defences along the coastal frontage

This paper describes the numerical modelling approach applied to assess coastal infrastructure resilience to climate change, as well as potential adaptation measures to mitigate any risks. The final aim of the study is to provide a long-term resilience strategy for the infrastructure.

Utilising state of the art methods for a joint probability assessment of nearshore wave and sea level conditions, Section 2 of the paper outlines how wave overtopping conditions were assessed for the range of different structure types along the open coast. The calibration of the modelling approach in this area using historical data is presented in Section 3.

The modelling approach and some of the results obtained along the two estuaries, the Exe and Teign, are discussed in Section 4.

The climate change scenarios and the adaptation measures considered in the analysis and their impact on the results are presented in Section 5. The approach and the results obtained are discussed in Section 6.

\section{Wave overtopping modelling approach}

\subsection{Introduction}

The methodology to determine overtopping rates for each of the defences considered along the coastal frontage was that applied in the National Flood Risk Assessment study for the Environment Agency [3]. This comprised three main components (Figure 3) which were:

- Multivariate (joint) probability analysis - offshore wave and wind data are combined with sea level data which are then extrapolated to extreme values.

- Offshore wave transformation - as waves propagate from offshore to nearshore they undergo wellknown physical process transformations that include refraction, shoaling and wave breaking. The offshore wave conditions were translated nearshore taking account of these processes.

- Wave overtopping/overflow discharges - wave and sea level conditions at the structure were transformed to overtopping discharges using wellestablished formulae, which were then analysed to determine extreme estimates.

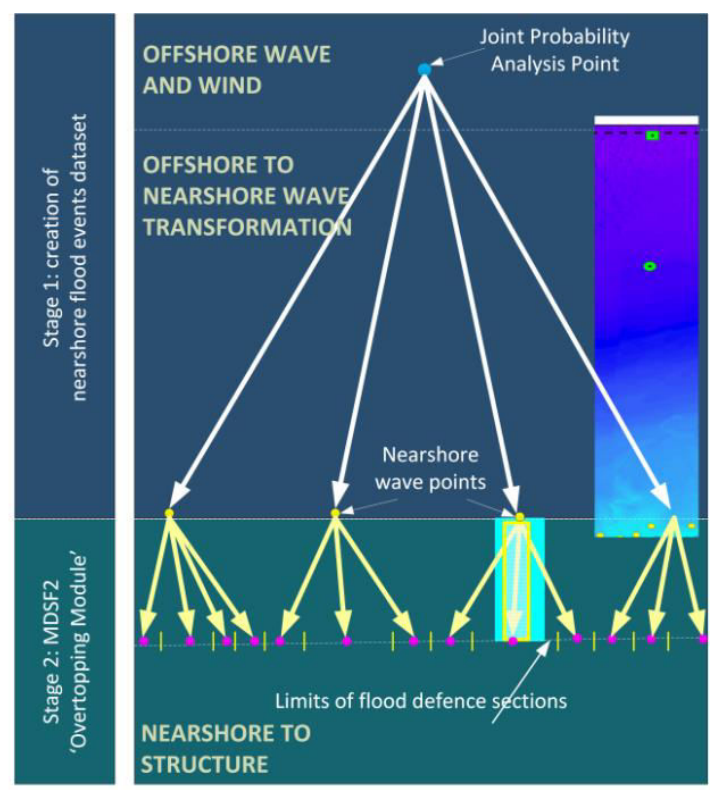

Figure 3. Conceptual diagram showing the components of the analysis methodology

This section outlines these different stages and how these were utilised in the project.

\subsection{Offshore multivariate extreme value analysis}

The analysis of offshore conditions is based on the method developed by Heffernan and Tawn [4], utilising concurrent records of sea level and wind and wave height records. The Heffernan and Tawn method enables extrapolation of the joint probability density of offshore waves, winds and sea levels to extreme values, whilst ensuring the appropriate dependencies between the different variables is captured. Further justification for 
the use of this model in the context of coastal wave and water level analysis and flood risk modelling is outlined in, for example, [5-8].

Based on this approach, a Monte Carlo simulation of concurrent wave, wind and sea levels was generated utilising an initial data set stretching back to 1980 .

The wave and wind data were provided from an extensive hindcast of the Wavewatch III model run by the UK Met Office. Sea level data was based on the existing Environment Agency tide gauge at Exmouth. Extreme sea levels were imposed on the analysis utilising published data on extremes around the English coastline [9]. These were updated to the present accounting for likely changes in sea levels and land level changes since these estimates were published [1-2].

The output from this analysis was a large number of joint parameters of the following variables representative of 10,000 years of concurrent conditions:

- $\quad$ Significant wave height, Hs (m);

- Wave period, Te (s),

- Wave direction $\left(^{\circ}\right)$,

- Wind speed $(\mathrm{m} / \mathrm{s})$,

- Wind direction $\left({ }^{\circ}\right)$,

- Directional Spreading,

- Sea level

Sample pairwise plots of four of these variables are shown in Figure 4.

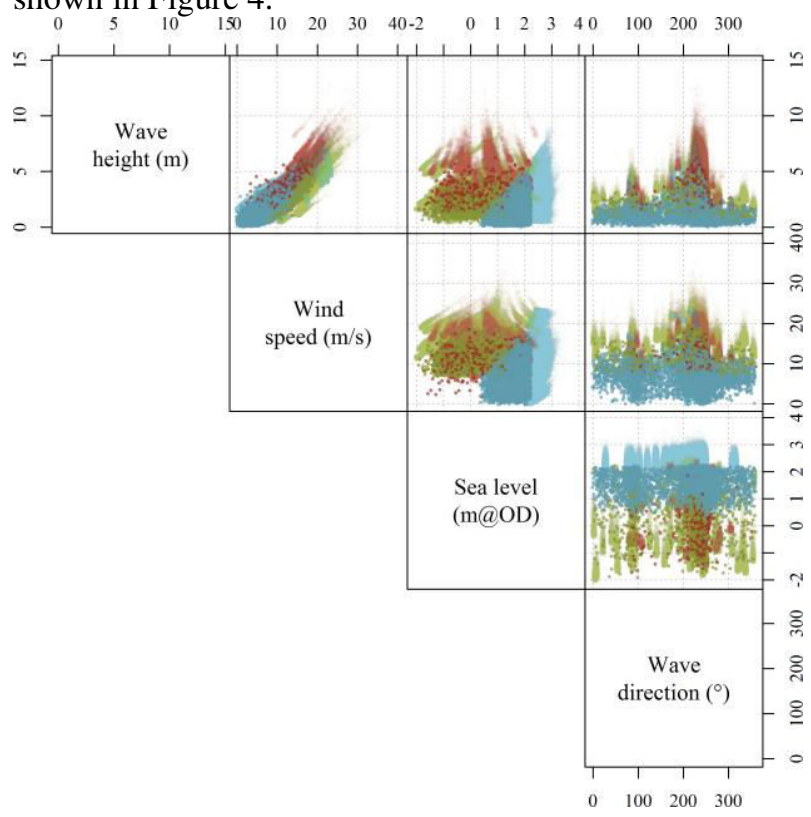

Figure 4. Pairwise scatter plot of sample of simulated values representative of 10,000 years offshore of Dawlish

\subsection{Wave transformation modelling}

Waves were transformed to the nearshore zone using the SWAN 2D wave transformation model [10]. The results were output at $1 \mathrm{~km}$ spacings at the $-5 \mathrm{mOD}$ contour, approximately $500 \mathrm{~m}$ offshore. The model was set-up for a variable water level across the grid to account for the spatial variation in sea levels across the model domain, based on the sea level defined at the tide gauge at Exmouth.
However, with 10,000 years of records to transform nearshore, an approach was required that would limit the time to model wave conditions. For the model used in this study, approximately $1,000,000$ events from the 10,000 year data set required modelling. Running each event through SWAN was not feasible computationally considering the time taken to run just one event. A traditional "look-up table" approach used in coastal flood forecasting systems was an option; however the number of parameters to represent (seven), would still result in significant computational effort. For example, a look-up table of 5 values per parameter would still equate to nearly 80,000 event runs. An emulator approach was therefore adopted, which was based on a relatively small number of design points that could represent the model space to a similar level of accuracy as a "look-up table" approach, but with a fraction of the number of model runs.

The development of the emulator involves running the SWAN model for a subset of events. Interpolation techniques are then applied to predict the results for other events not run in SWAN $[10,11]$. Traditional look up table approaches are typically applied using linear interpolation techniques. As the output from SWAN is generally not a linear function of the inputs, these traditional look-up tables can be inefficient and therefore require a large number of simulations. There has however been extensive research into more sophisticated interpolation techniques, in particular Gaussian Process Emulators (GPE's), e.g. [11]. These more sophisticated approaches have been shown to be efficient when used in the context of wave transformation modelling [12, 13]. This is demonstrated in Figure 5 for example which shows the efficiency gains that are possible, compared to a traditional "look-up table" approach when applying a GPE to the SWAN wave model. It is evident that the same Root Mean Squared Error (RMSE) of the significant wave Height, $\mathrm{H}_{\mathrm{s}}$, was achievable with 70 runs of the SWAN model using a GPE when compared to more than 48,000 runs using the traditional look-up table approach.

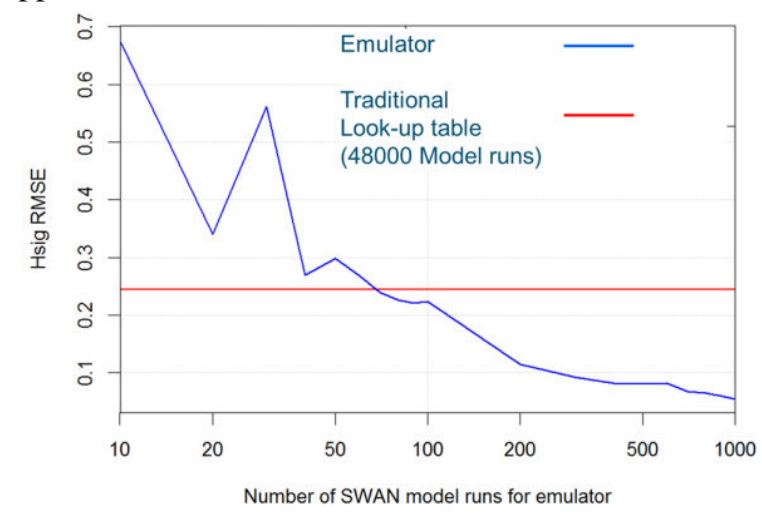

Figure 5. Route Mean Square Error as a function of design point simulations - comparison between a GPE and a traditional "look up" table approach

An emulator was therefore used to translate the design points through to each of the nearshore locations, with a separate emulator created for each location. The extreme 
water levels from [9] were then imposed on each nearshore point. Once created, the emulator was used to translate all of the events within the large sample, through to the nearshore points. To select the design points to cover the input boundary condition space, the maximum dissimilarity algorithm [14] was used, with further refinements described by [15].

The wave characteristics at the nearshore points were transformed to the toe of the coastal defence structures through the use of the SWAN 1D wave model. These data were then used as input for the overtopping calculations described in the next section.

\subsection{Overtopping estimation}

The prediction of mean overtopping discharges (MOTD) over the defence structures along the coastal frontage, which included both vertical and sloping structures, was estimated according to the safety assessment empirical formulae of EurOtop Manual [16]. It should be noted that these are stated as being accurate to approximately one order of magnitude. Figure 6 shows a sketch of a typical cross section of a sea defence and the parameters involved in the calculation of the MOTD. Parameterisation of each defence along the coastal frontage was based on this definition sketch. This enabled vertical or sloping walls with or without a berm and/or set-back wall to be defined easily for overtopping calculations.

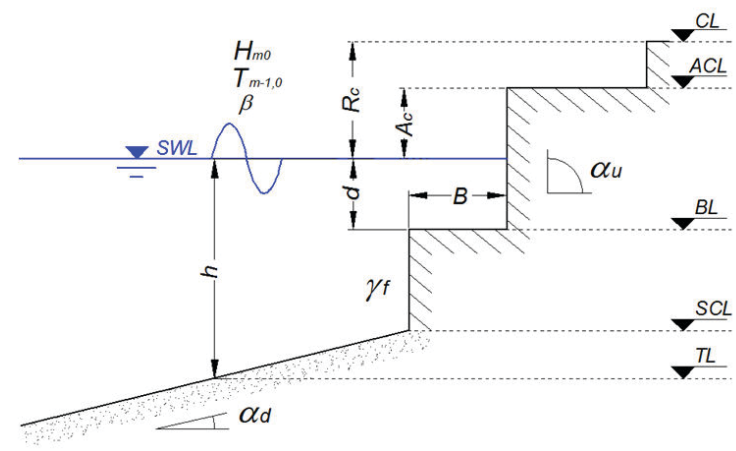

Figure 6. Sketch of the parameters involved in the calculation of the mean overtopping discharge

The steps involved in the selection of the relevant equations to estimate wave overtopping were:

- Definition of the different levels of the defence relatively to the local datum, OD (as per Figure 6);

- Definition of the cross-section parameters in accordance to EurOtop Manual (as per Figure 6): slightly different considerations were made for vertical or sloping defences;

- Definition of the incident wave characteristics: the position where wave characteristics (i.e. wave period and wave height) are considered for the calculation of the MOTD can be different with the variation of the sea water level, the beach profile and the type of the structure (i.e. vertical wall or sloping structure);

- Selection of the most appropriate overtopping equation of EurOtop Manual: for sloping structures distinction was made between breaking and nonbreaking wave conditions (Chapter 5 and 6 of the EurOtop Manual); for vertical structures the wave impact was characterised as impulsive, non-impulsive or broken-waves condition (Chapter 7 of EurOtop Manual).

The results of the analysis were overtopping rates corresponding to different return periods for each defence structure within the study area. Overtopping discharges were calculated at the top of the crest of the defence and at the promenade level or armour crest, $C L$ and $A C L$ respectively in Figure 6.

Overtopping return periods were determined by ranking the samples representing the 10,000 years of data from the highest to the lowest with the cumulative probability $p_{i}$ assigned to the $i^{\text {th }}$ smallest overtopping rate via the formula:

$$
p_{i}=\frac{i-a}{n+1-2 a}
$$

where $\alpha$ is the plotting position parameter and $n$ the number of samples.

Empirical return periods were then assigned using the formula:

$$
T_{i}=\frac{n_{y}}{n\left(1-p_{i}\right)}
$$

Where $n_{y}$ is the number of years of simulation. For the plotting position parameter Hazen's formula where $\alpha=0.5$ [17] was used. The choice of the plotting position formula was though not significant as alternative formulas only have a significant effect on the period assigned to the largest values which were not used as only return period estimates up to 1,000 years, a tenth of the data set, were used. These results were analysed to determine a distribution (return periods) of overtopping rates.

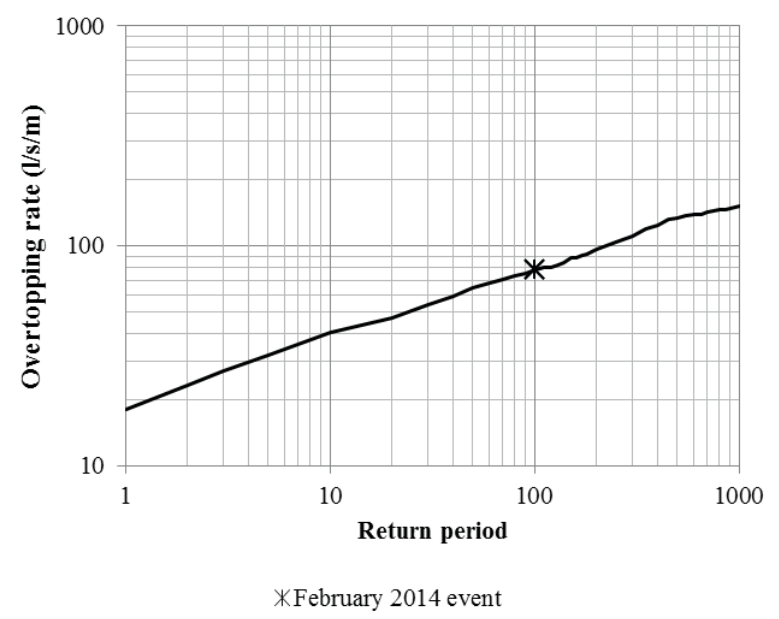

Figure 7. Example of overtopping curve along one section of the coastal frontage (at Dawlish)

A sample analysis is shown in Figure 7 which shows the overtopping rate against return period for a vertical wall. Also shown on this figure is the hindcast overtopping rate corresponding to the 2014 storm event. This indicates 
that this event had an overtopping return period of approximately 100 years.

\section{Hindcasting analysis}

To assess the performance of the modelling system to estimate overtopping rates, a hindcast analysis was undertaken to identify times of past overtopping rates. The simulation covered a period of 35 years, from 1980 to 2014. The results of the simulation were compared with anecdotal and observational evidence of wave overtopping occurring along the frontage obtained from different sources.

A review of the available documentation identified 17 events as "likely" overtopping-related incidents at the coastal frontage. As an example, Figure 8 shows the main incidents of trains reported as delays of their running time (expressed as minutes).

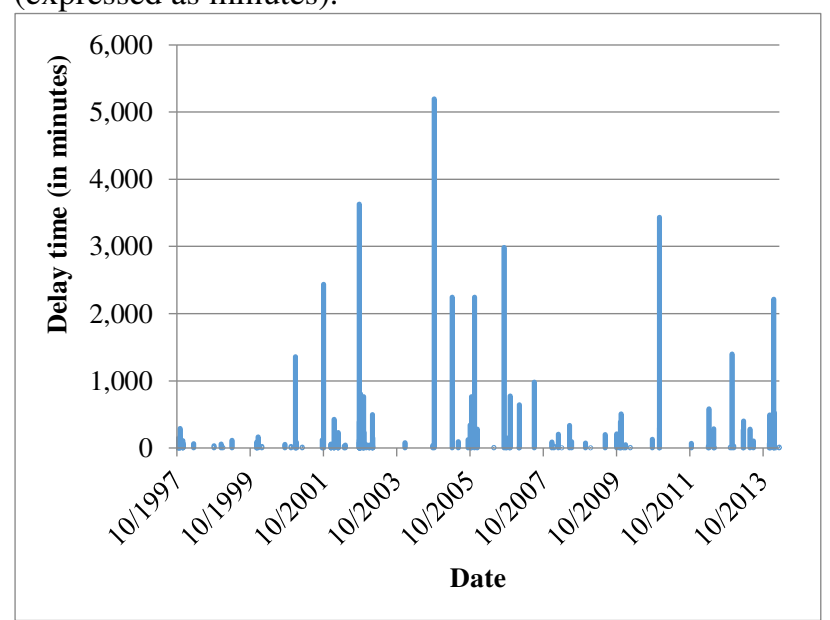

Figure 8. Main flooding events during the period 1997-2014 expressed as time delay of railway operation

As already noted, one of the main events occurred on the night of 4-5 February 2014 when strong southerly winds resulted in rough seas and significant wave action along much of the coastline of Devon and Cornwall. Occurring during a time of large spring tides, this resulted in sea levels with a return period of at least 1 in 5 years being observed along most of this coastal stretch. As a consequence, the south-west mainline suffered a major breach at Dawlish, with around $40 \mathrm{~m}$ of the seawall at this location destroyed. The line was closed, not opening until almost 9 weeks later, on $4^{\text {th }}$ April.
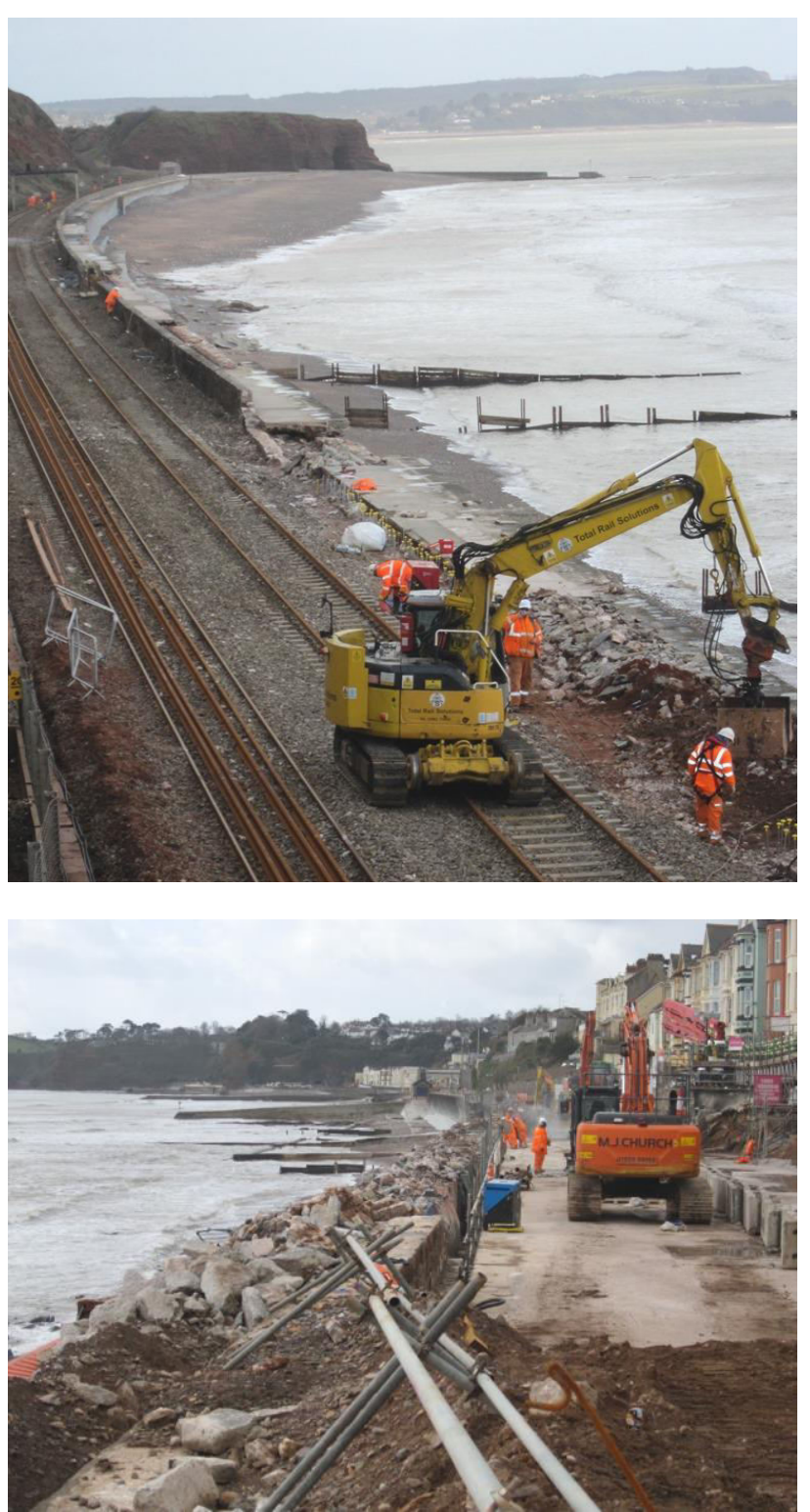


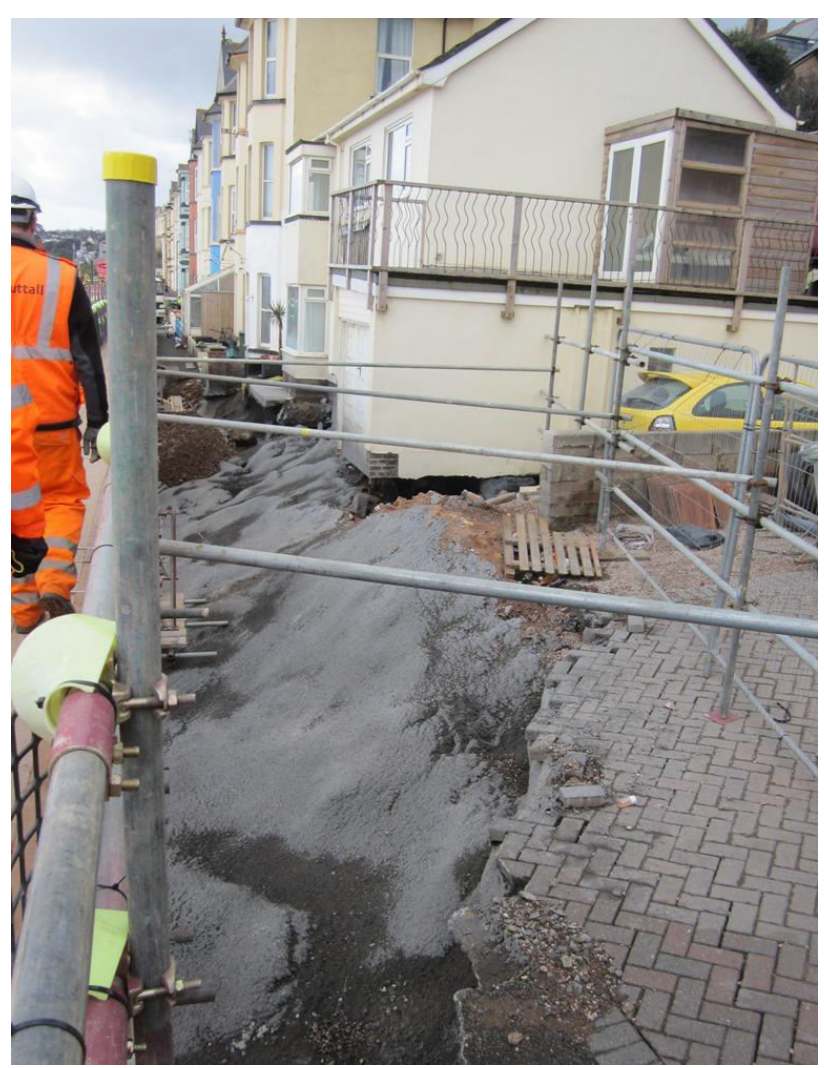

Figure 9. Pictures of the damage occurred on the railway line at Dawlish in February 2014

The key problems to the railway during extreme weather events have been identified as seawater reaching sensitive electrical control components on the trains when considerable quantities of salt water are projected upwards and/or sideways from the seawall. These problems may be specific to the particular train type, but heavy wave overtopping has the potential to cause more widespread or serious problems to all trains ranging from:

- derailment risk driven by direct sideways impact onto the train;

- direct impact (water and sediment) breaking train windows;

- hazards to staff on the rail line;

- flow depths / velocities causing a person to lose their footing and/or backwash flows carrying a person into the sea;

- direct wave damage to track bed materials and trackside infrastructure;

- $\quad$ flooding of track bed.

For the hindcasting analysis overtopping rates were calculated for each defence, in some cases considering different possible beach profiles for each of the 17 identified events.

The results from the hindcasting analysis were consistent with the most significant overtopping events matching anecdotal evidence. For example, the February 2014 event, that caused the collapse of the line, was the one with the highest overtopping rate in this region. This gave the confidence that the analysis correctly predicted times when the greatest levels of overtopping occurred, and therefore provides confidence in the overtopping assessment.

\section{Modelling approach at the Exe and Teign Estuaries}

Hydraulic models were developed to simulate the propagation of flood water over the floodplain and thus, over the railway line, along the Exe and Teign Estuaries.

An existing Environment Agency model (1-2D ISISTUFLOW) was used for the Exe Estuary [18]. The Estuary channel sections were simulated with a 1D approach, and the floodplain with a 2D approach based on a regular $10 \mathrm{~m}$ grid. Tributaries, outfalls and raised infrastructure were also included in the model. Along the Estuary, the defences are a combination of vertical walls and embankments with sandy foreshore.

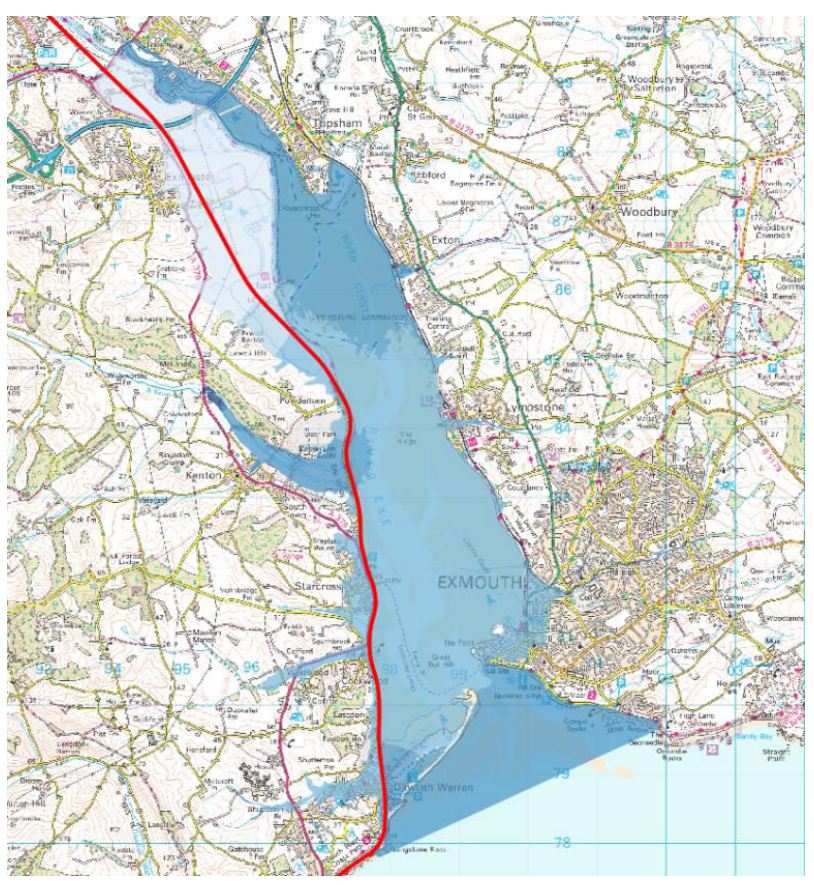

Figure 10. Area modelled along the Exe Estuary

A new model of the Teign Estuary was set up with Infoworks 1D-2D. The general approach was similar to the one in the Exe Estuary: the main Estuary simulated in $1 \mathrm{D}$ and the floodplain in 2D. LIDAR data was used to define the geometry of the study area and more detailed information was used to update levels and identify existing defence levels where the railway line is located.

The models were run for different scenarios considering an average discharge from the river, corresponding to a return period of 2 years, and different boundary conditions downstream associated with the sea level conditions. Four different return periods, corresponding to $10,75,200$ and 1,000 years, were considered for the sea level conditions.

The Exe Estuary model identified high water levels for the 10 years return period scenario. It has to be noted that crests level of some defences are similar to sea levels under present day conditions. 
The results in the Teign Estuary showed only a very small area at risk of flooding for the 200 return period scenario (Figure 11).

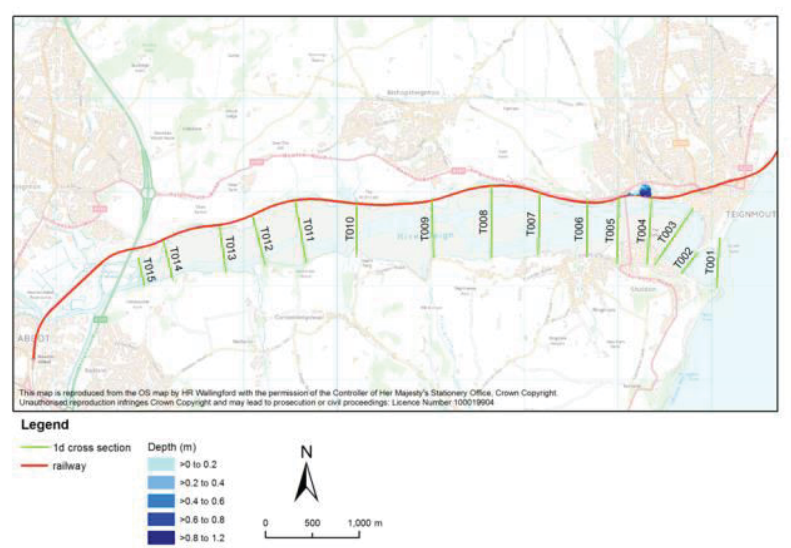

Figure 11. Flooded area along the left bank of the Teign Estuary (near section T004) for the 1,000 return period of tides

\section{Climate change and adaptation measures}

The climate change scenarios modelled (Table 1) considered sea and surge level rises, as well as increases in river flows occurring in 50 and 100 years' time and for three emission scenarios, low, medium and high. These were extracted from [9] for changes in storm surge and river flow and [19] for sea level rise, specific to Dawlish.

\begin{tabular}{|c|c|c|c|c|c|c|}
\hline \multirow{2}{*}{$\begin{array}{c}\text { Climate } \\
\text { metric }\end{array}$} & \multicolumn{3}{|c|}{ Year 2065 } & \multicolumn{3}{c|}{ Year 2115 } \\
\cline { 2 - 7 } & Low & Med & High & Low & Med & High \\
\hline $\begin{array}{c}\text { Sea Level } \\
\text { Rise (m) }\end{array}$ & 0.26 & 0.30 & 0.55 & 0.48 & 0.57 & 1.06 \\
\hline $\begin{array}{c}0.5 \% \\
\begin{array}{c}\text { Probability } \\
\text { storm Surge } \\
\text { (m) }\end{array}\end{array}$ & \multicolumn{3}{|c|}{0.47} & \multicolumn{3}{c|}{1.05} \\
\hline $\begin{array}{c}\text { River } \\
\text { Flows (\%) }\end{array}$ & 1.7 & 23.3 & 51.7 & 10 & 40 & 110 \\
\hline
\end{tabular}

Table 1. Climate change conditions considered in the modelling approach

The sea level rise considered in the modelling approach was calculated taking into account the probability of a storm surge based on the following rules:

- $\eta_{\mathrm{wl}}<\eta_{\mathrm{MHWS}}$, slr $=\mathrm{msl}$

- $\eta_{\text {MHWS }}<\eta_{\mathrm{wl}}<\eta 50$, slr $=\operatorname{msl}+\operatorname{sur}\left(\eta_{\mathrm{wl}}-\eta_{\mathrm{MHWS}}\right) /$ $\left(\eta_{50}-\eta_{\text {MHWs }}\right)$

- $\eta_{\text {MHWS }}>\eta_{50}$, slr $=$ msl + sur

Where: slr = total sea level rise; $\mathrm{msl}=$ mean sea level rise; sur $=$ storm surge rise; $\eta_{\mathrm{wl}}=$ water level being considered; $\eta_{\text {MHWS }}=$ mean high water spring value; $\eta_{50}=$ 50 year extreme sea level.

Overtopping rates were calculated for the 6 climate change scenarios outlined in Table 1 , for 40 different return periods up to 1,000 years. This was done for the
37 defence sections that were schematised to represent the total coastal frontage.

Along the estuaries, the numerical modelling results provided flood extents (Figure 10) and water levels. In the estuaries, still water flooding levels were considered the dominant source of flooding.

Some of the adaptation measures considered to tackle the future climate change impacts included the raising of crest levels of defences along the coastal frontage and the estuaries to different elevations, the creation of revetment slopes and "set-forward" sea walls in front of the existing coastal defences and the consideration of detached low defences located nearshore approximately $100 \mathrm{~m}$ in front of some of the existing ones. The numerical results of the different adaptation measures are discussed in the following section.

\section{Discussion of results}

The potential impacts of climate change on a key section of coastal railway infrastructure have been assessed. The results obtained from the modelling clearly demonstrate the potential effect that climate change can have on overtopping results and water levels for the defences in this region, and thus for the railway line. An example of the results obtained for a sample of return periods is given in Figure 12.

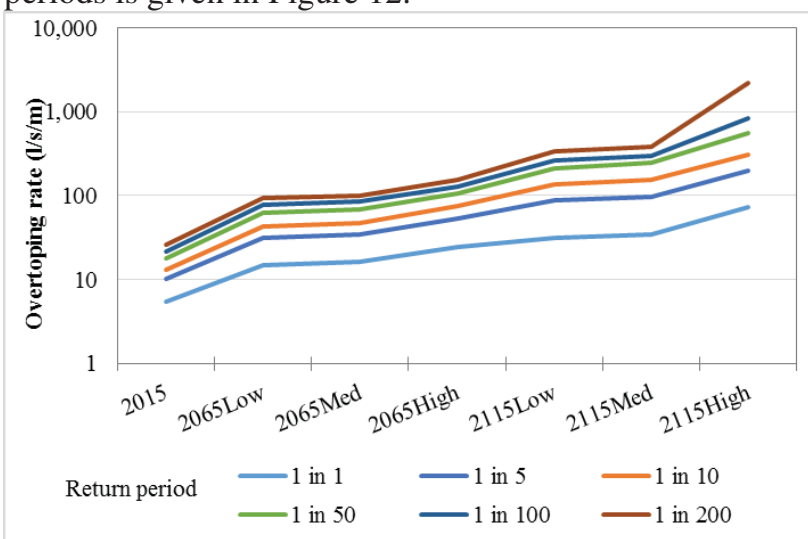

Figure 12. Overtopping rates for the present day conditions and the different climate change scenarios for one defence

In the coastal frontage, the results showed that, for some of the defences, the present 40 year overtopping rate will become less than an annul event by 2065 under the low emissions scenario. For different, more extreme scenarios, overtopping rates will become significantly more extreme, particularly by 2115 .

Potentially major structural damage is likely to make the operation of the railway line unsustainable for rates above approximately $10-100 \mathrm{l} / \mathrm{s} / \mathrm{m}$. The upper limit of this range is likely to be reached by the 1 in 110 year event for most defences under the 2065 medium emissions scenarios, and by the 1 in 10 year event for most defences under the 2115 medium emissions scenarios.

The sea level rise and surge increase of the climate change scenarios in the Exe and Teign Estuaries cause a 
considerable increase in the probability of the track being flooded.

In the Exe Estuary the results show how the railway is consistently flooded by lower return periods. In particular, almost the whole line is flooded for the 2115 Medium scenario when considering the lower return period of 10 years.

A range of mitigation options have been tested and the performance assessed over the range of scenarios. This analysis has identified a set of preferred solutions for the different geographic areas. This analysis has then formed the basis of discussion with Network Rail and is being used to support and aid their development of a climate resilient adaptation plan.

The modelling results show that the rock revetment slope in front of the existing defence substantially reduces overtopping rates in all scenarios.

When moving through the different climate change scenarios considered (from 2065 low to 2115 high), the results show that the crest level has a greater effect on reducing overtopping levels than the toe level and the roughness of the rock. This implies that when considering the best adaptive measure, whether a rock revetment slope or a seawall, the option that will become more effective at reducing overtopping rates, and a more favourable option for the higher scenarios in the longer time period, would be the one with highest crest levels.

When considering a "set-forward" seawall in front of the existing one, numerical results can show greater levels of overtopping than the existing seawall, despite the increased height of the new seawall. This is a result of the reduced toe level having a greater effect on overtopping rates than the raised crest height. In addition, it has to be considered the reduction in overtopping due to distance or any permeability of the structure immediately behind the defence line. In this case, the placement of a short stub-wall or a similar option at the rear of the advanced seawall option would noticeably reduce overtopping levels.

In the Exe Estuary, the adaptation measures considered, which increased the defence crest levels, were able to decrease water levels below the railway line elevation for the 2065 Medium emissions scenario, although flooding was still observed in the upstream area for the 1000 return period event.

The uncertainties associated with climate change are well-documented and hence a scenario-based approach was adopted. The scenarios considered do not have any particular likelihood associated with them, rather they are considered plausible outcomes that capture the range of potential change. It is therefore desirable for mitigation options to perform well within the range of scenarios considered, without introducing excessive costs and overconservative designs.

\section{References}

1. University of Colorado Sea Level Research Group. (2016), Global Mean Sea Level, accessed 22 February 2016, <http://sealevel.colorado.edu $>$.
2. Bradley S., Milne G.A., Teferle F. N., Bingley R. M. and Orliac E. J. (2008). Glacial isostatic adjustment of the British Isles: New constraints from GPS measurements of crustal motion. Geophysical Journal International, 178(1), 14-22.

3. HR Wallingford (2016). NaFRA State of the Nation: Final Project Report. Report MCR5289-RT030R01-00 (in draft).

4. Heffernan J. E. and Tawn J. A. (2004). A conditional approach for multivariate extreme values. Journal of the Royal Statistical Society, Series B (Statistical Methodology), 66(3), 497-546.

5. Wyncoll and Gouldby (2014) Application of a multivariate extreme value method to flood risk analysis, J. Flood Risk Man. 8(2), 142.

6. Gouldby B, Mendez F, Guanche Y, Rueda A and Minguez R (2014) A methodology for deriving extreme nearshore sea conditions for structural design and flood risk analysis, Coast. Eng, 88.

7. Lamb R., Keef C., Tawn J., Laeger S., Meadowcroft I., Surendran S., Dunning P. and Batstone C. R. (2010). A new method to assess the risk of local and widespread flooding on rivers and coasts. Journal of Flood Risk Management, 3(4): 323-336..

8. Keef C., Papastathopoulos I. and Tawn J. A. (2013). Estimation of the conditional distribution of a multivariate variable given that one of its components is large: Additional constraints for the Heffernan and Tawn model, Journal of Multivariate Analysis, 115, 396-404.

9. Environment Agency. (2011). Coastal flood boundary conditions for UK mainland and islands. February 2011.

10. Booij N., Ris R.C. and Holthuijsen L.H. (1999). A third-generation wave model for coastal regions: 1 . Model description and validation. Journal of Geophysical Research, 104(C4, 7649-7666.

11. Kennedy M.C., Anderson C.W., Conti S. and O’Hagan A. (2006). Case studies in gaussian process modelling of computer codes. Reliability Engineering \& System Safety, 91(10), 1301-1309.

12. Camus P., Mendez F.J. and Medina, R. (2011a). A hybrid efficient method to downscale wave climate to coastal areas. Coastal Engineering, 58(9), 851862.

13. Camus P., Mendez F.J. Medina R. and Cofiño A.S. (2011b). Analysis of clustering and selection algorithms for the study of multivariate wave climate. Coastal Engineering, 58(6), 453-462.

14. Kennard, R.W. and Stone, L.A., 1969. Computer aided design of experiments. Technometrics, 11(1): 137-148.

15. Willett P. (1999). Dissimilarity-based algorithms for selecting structurally diverse sets of compounds. Journal of Computationally Biology. 6(3-4): 447 457.

16. Pullen T., Allsop N.W.H., Bruce T., Kortenhaus A., Schüttrumpf H. and van der Meer J.W. (2010). "EurOtop: wave overtopping of sea defences and related structures: assessment manual. Overtopping course edition". HR, Wallingford Ltd. 
17. Hazen, A., 1914, Storage to be provided in the impounding reservoirs for municipal water supply: Transactions of the American Society of Civil Engineers, v. 77, p. 1547-1550.

18. Mott MacDonald (2012) Exe Estuary Mapping \& Modelling study. For the Environment Agency.

19. Met Office. (2016) UK Climate Projections (UKCP09), accessed 22 February 2016, <http://ukclimateprojections.metoffice.gov.uk/>. 